\title{
A Mechanics-Based Procedure for Predicting Groundwater-Rise-Induced Slope Displacements
}

\author{
Ching-Chun Huang* \\ Professor, Department of Civil Engineering, Taiwan
}

Received: 制 November 12, 2018; Published: 制 November 27, 2018

*Corresponding author: Ching-Chun Huang, Professor of Department of Civil Engineering, National Cheng Kung University, Taiwan, Email: samhcc@mail.ncku.edu.tw

\begin{abstract}
A procedure for predicting cumulative slope displacements induced by groundwater table changes is proposed. The proposed procedure incorporates a back-calculation technique for the soil strength parameter based on the records of slope displacement and ground water table changes. The analytical tool for the back-calculation is a limit-equilibrium-based finite displacement method (FFDM) requiring force and moment equilibrium, displacement compatibility, and a hyperbolic shear stress-displacement constitutive law. The analyzed potential sliding mass is a statically determinate system, providing a closed-form solution for the displacement of the slope. Two well documented case histories of periodic rainfall-induced slope displacements are used to validate the proposed analytical procedures. The hyperbolic soil strength parameters back-calculated from the first event of slope displacement can be used as operational soil strength parameters for predicting subsequent slope displacements caused by rainfall-induced groundwater table elevation changes. The proposed method alleviates possible difficulties associated with the evaluation of soil strength using undisturbed soil sampling of colluviums in foothill areas. The proposed method requires little computer time in deriving useful information of slope displacement which cannot be achieved using conventional limit equilibrium methods or advanced numerical analyses. The proposed analytical procedure is valid only for simulating instantaneous sliding where time-dependent viscous (or creep) deformation is not dominant.
\end{abstract}

\section{Introduction}

A substantial part of the infrastructure damage and remediation budget is used to fix damage caused by slope failures $[1,2]$. Therefore, analyses for slope failure potential in response to environmental changes, such as intensive rainfall, seismic activities [3] or groundwater level changes [4] is necessary for facilitating maintenance and disaster mitigation programs. Various analytical methods have been developed for slope stability evaluations. In the study of important and large-scale infrastructure such as dams or metropolitan shield tunnels where failures are lifethreatening, sophisticated numerical methods, such as the finite element method (FEM) and the finite difference method (FDM), are desirable [5]. In such cases, sufficient budgets for intensive ground explorations, computer analysis, and skillful computational engineers are needed. In reality, studies on slope stability are frequently time- and budget-limited, and a numerically accurate (or sophisticated) computer analysis often makes numerous assumptions regarding the underground geological or geo environmental conditions. A complete numerical analysis with totally known material properties and underground environmental conditions is rare. This may explain why limit equilibrium methods, in which the displacement (or strain) is not an analytical outcome,

are still popular among geotechnical engineers in studying slope engineering problems. Most conventional limit equilibrium slope stability methods are based on the principle of limit equilibrium (or force equilibrium), providing a single value of safety factor (Fs) for the analyzed slope without considering displacement-related information for the potential sliding soil mass. A time-efficient tool capable of calculating slope displacements is necessary. A forceequilibrium-based finite displacement method (FFDM) proposed by Huang [4] developed to fulfill this need.

\section{Methodology}

The method of FFDM proposed by Huang [4] and extended by Huang [6], Huang and Yeh [7] and Huang [8] constitutes the core of back-calculations and predictions discussed in the following. It has been previously shown that for a sliced potential failure mass confined by a slip surface with an arbitrary shape, as shown in Figure 1, the system is a statically determinate one. A constitutive law for the shear stress vs. shear displacement relationships based on the hyperbolic soil model (parameters: $\mathrm{K}, \mathrm{n}$, and $\mathrm{R}_{\mathrm{f}}$ ) for the soil constituting the slip surface is incorporated. In addition, the MohrCoulomb failure criterion (parameters: cohesion, $\mathrm{c}$ and internal 
friction angle, $\phi)$, and local safety factor, $\mathrm{F}_{\mathrm{Si}^{\prime}}$, the displacement compatibility between adjacent slices is considered by using displacement diagrams (displacement compatibility function $\left.f\left(\alpha_{i}\right)\right)$. The vertical displacement at the top of the potential sliding mass $\left(\Delta_{0}\right)$ and shear displacement along the sliding surface $\left(\Delta_{1}-\right.$ $\Delta_{\text {ns }}$; ns: total number of slices). Figure 2 shows the flow chart of the computer program SLICE-DISP for the proposed FFDM (See Appendix).

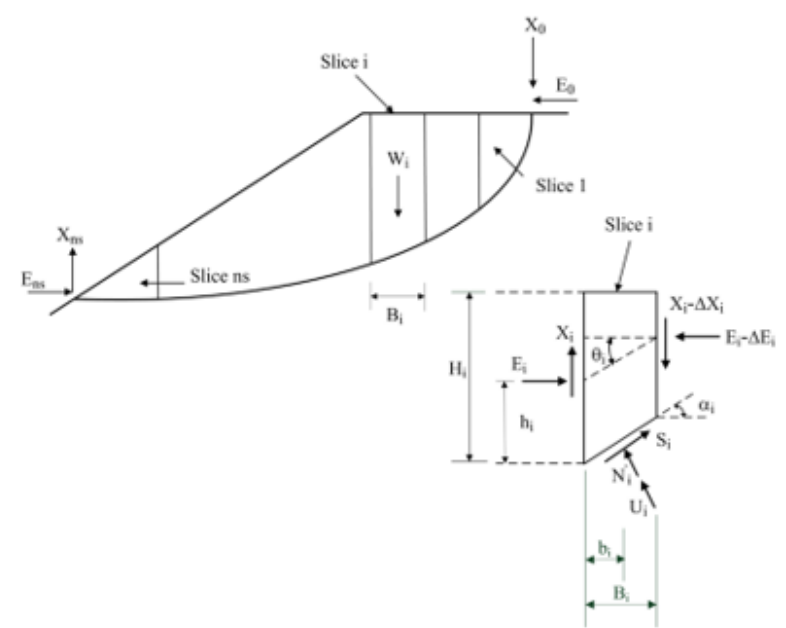

Figure 1: Force system for a sliced potential failure mass with an arbitrary shape.

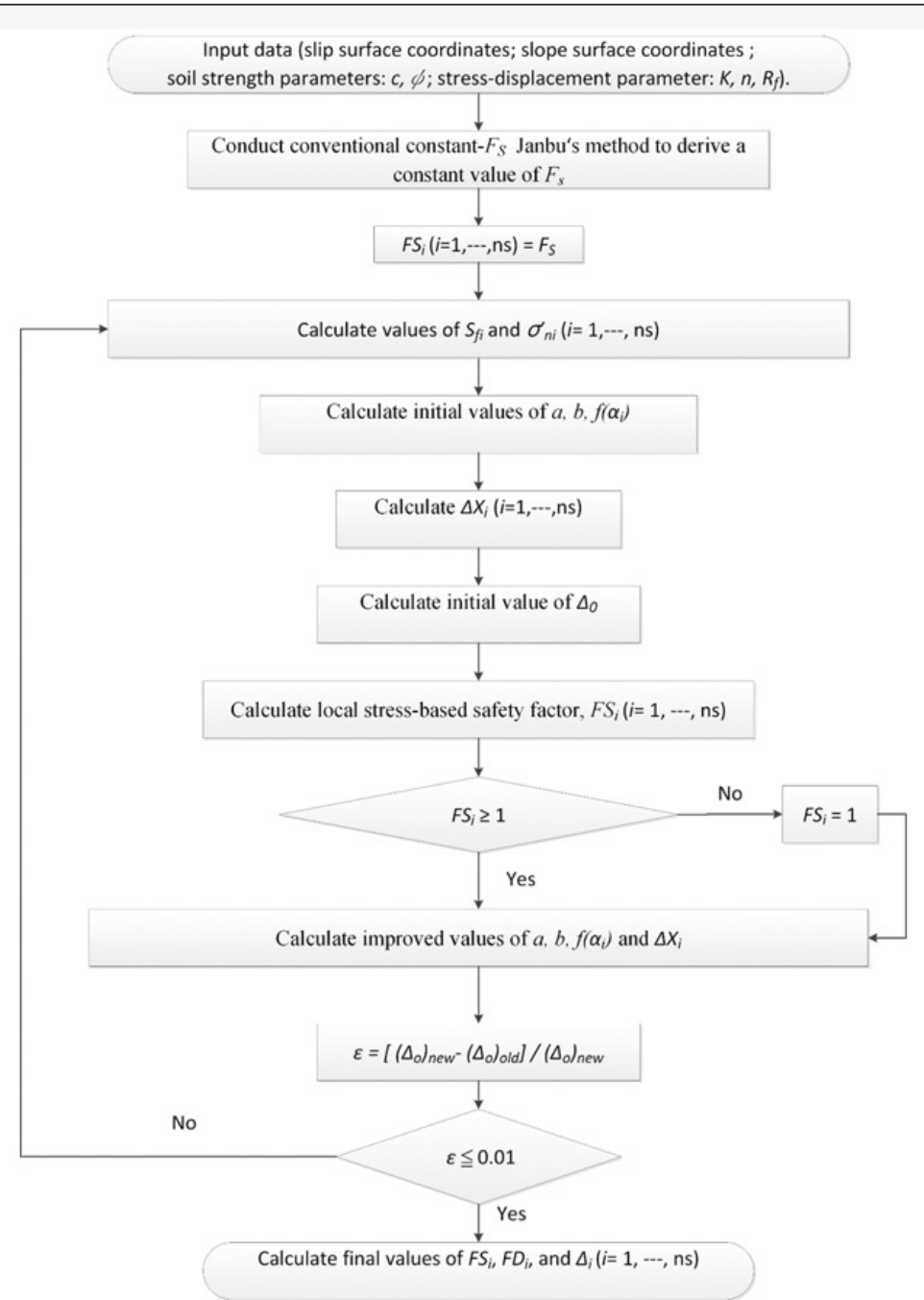

Figure 2: Flow chart for FFDM computer program consisting of the computation algorithm shown in APPENDIX. 


\section{Case History: Woo-Wan-Chai Slope}

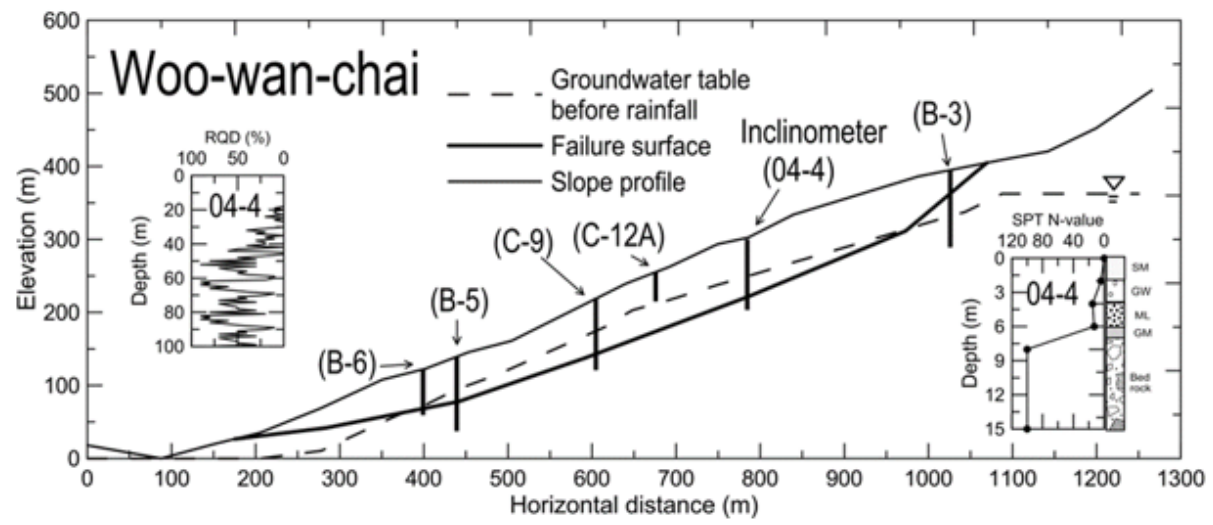

Figure 3: Slope profile for case history \#1 (Woo-Wan-Chai).
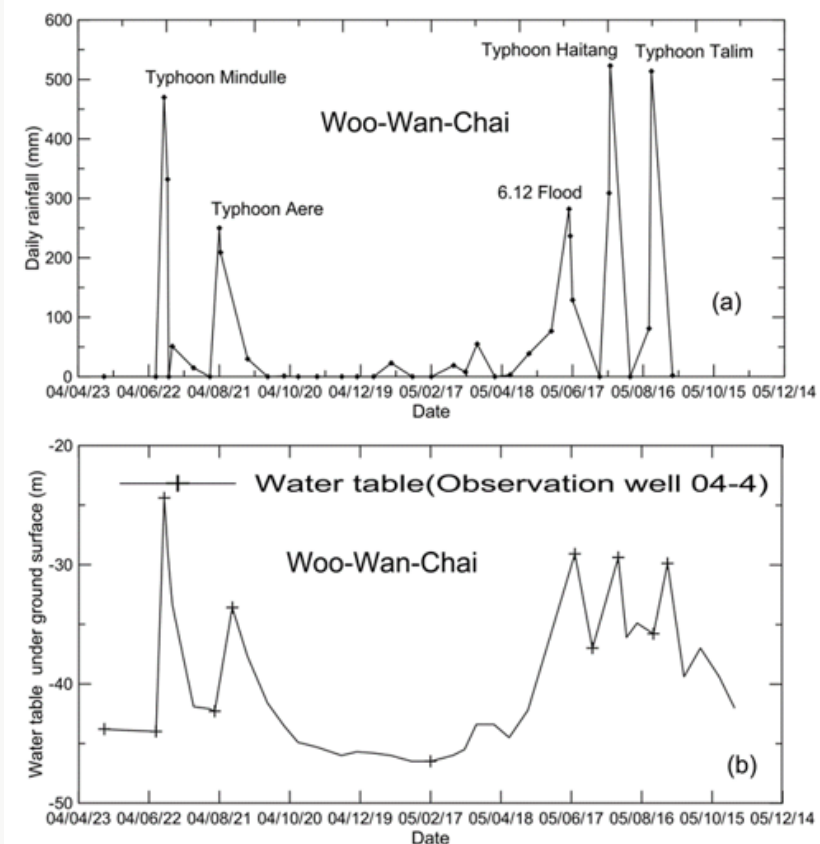

Figure 4: Records of long-term monitoring for case history \#2: (a) Daily rainfall; (b) Groundwater table heights

Figure 3 shows a cross section of the Woo-Wan-Chai slope $[9,10]$ consisting of alluviums. The slope is a part of a highway winding through the western foothills of Taiwan. The slope is subjected to rainfall-induced periodic displacements, requiring repeated remedial measures. Figures $4 \mathrm{a} \& 4 \mathrm{~b}$ show records of daily rainfall and groundwater table heights, respectively, during the period of May 2004 to October 2005. The majority of high daily rainfall is caused by typhoons. A close relationship between intensive rainfalls and rises of the groundwater table can be seen. The slip surface presented in Figure 3 is formed by connecting points of abrupt deflection detected by the inclinometers available in-situ. The slip surface reaches a maximum depth of about $90 \mathrm{~m}$ below slope surface. According to the values of Rock Quality Designation (RQD) as shown in Figure 3, the highly weathered rock strata have scattered RQD values, occasionally showing a low $\mathrm{RQD}=10 \%$, suggesting the investigated slip surface is associated very weak soil-like material. Due to the difficulty associated with undisturbed sampling in weathered rock stratum, soil shear strength can only be estimated indirectly from the values of RQD. Values of internal friction angles $(\phi)$ ranging between $26^{0}-35^{0}$ are assumed in the following analyses. The first event of heavy rainfall (or groundwater table rise), caused by typhoon Mindulle on July 1, 2004, is used for calibrating in-situ soil parameters $\mathrm{K}, \mathrm{n}$, and $\mathrm{R}_{\mathrm{f}}$ The measured groundwater tables before and after rainfall shown in Figure 3 are used in the calibration of the in-situ soil parameters. Figure 5 shows the safety factors of the slope (Fs) calculated using the Janbu's slice method Although the result of calibration is influenced by the use of various values of $\mathrm{c}$, the accuracy of slope displacement calculation 
is not with various input values of $\mathrm{c}$ and $\varphi$. It can be seen that during the period of monitoring, values of Fs varied to some extent according to the level of the groundwater table. However, these values of Fs suggest that the slope is stable and thus do not reflect the measured slope displacement.

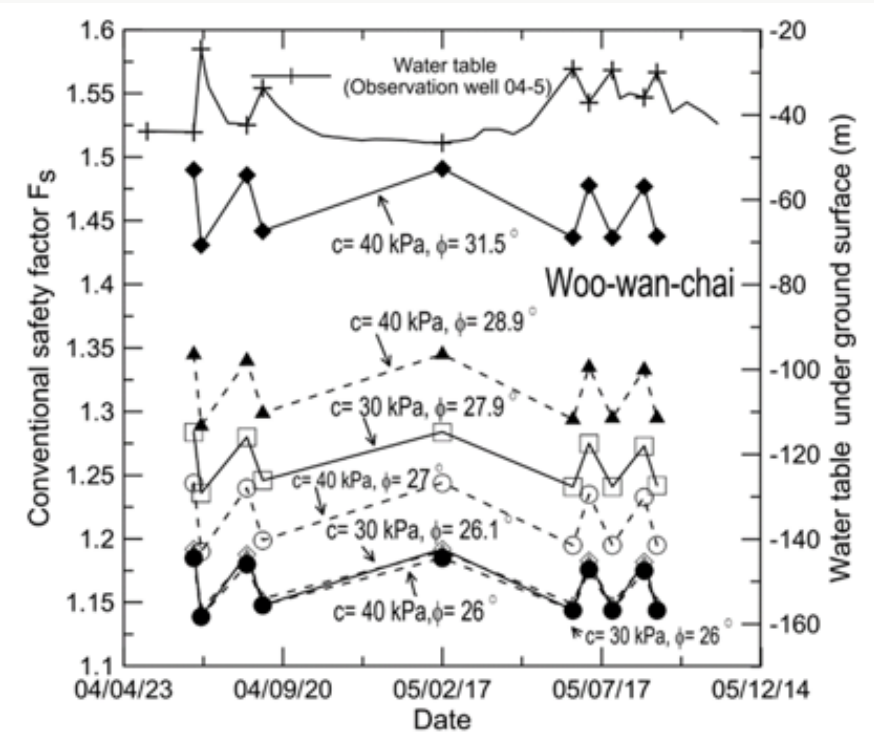

Figure 5: Conventional safety factors in response to the groundwater table fluctuations for case history \#1 (Woo-Wan-Chai).
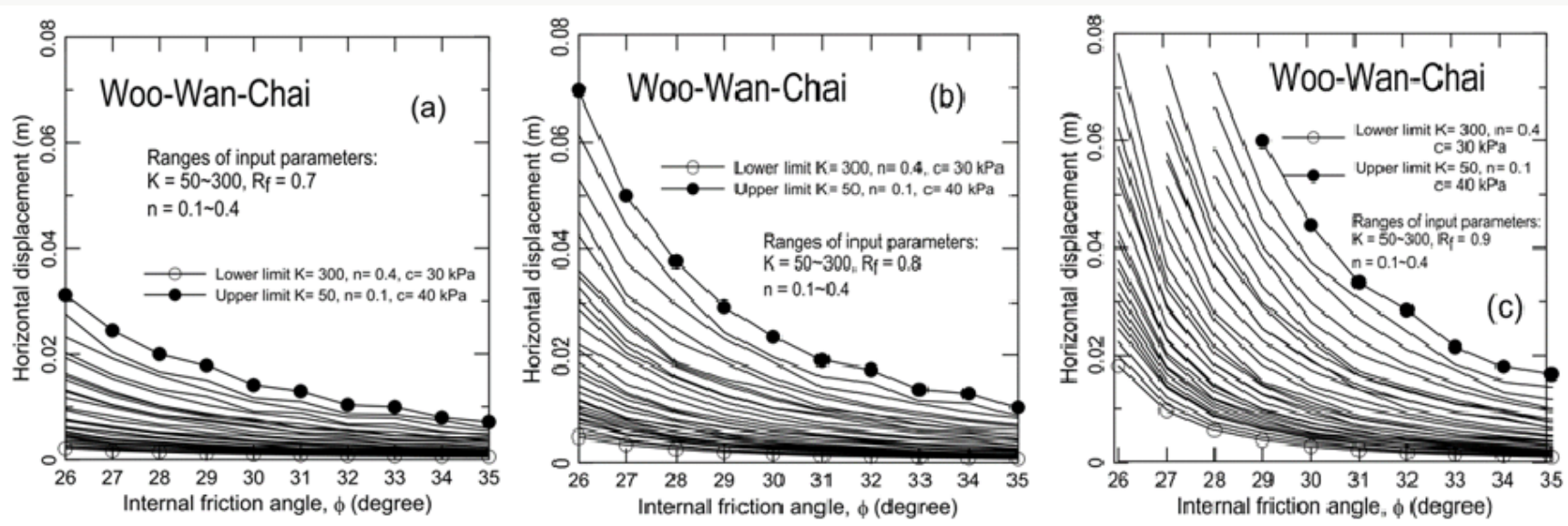

Figure 6: Results of parametric studies on case history \# 1 (Woo-wan-chai) using wide ranges of $K, n, c$ and $(a) R_{f}=0.7$; $(b) R_{f}=0.8$; (c) $R_{\mathrm{f}}=0.9$.
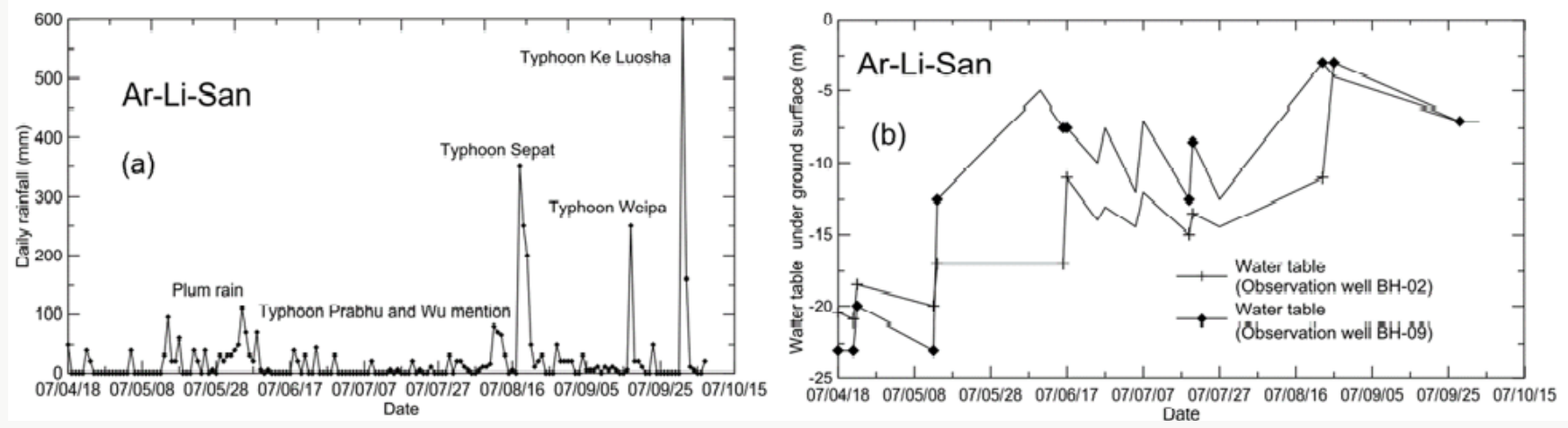

Figure 7: Records of long-term monitoring of case history \#2: (a) Daily rainfall; (2) Groundwater table heights. 
Figures 6(a-c) show the calculated horizontal displacement at the location of inclinometer 04-4 (which is $280.5 \mathrm{~m}$ from the crest of the slip surface) for the first rainfall event using $R_{f}=0.7,0.8$, and 0.9 , respectively. In Figures 6(a-c), values of $K=50,100,200,300$; $n=$ $0.1,0.2,0.3$, and $0.4 ; \varphi=26^{0}-35^{\circ}$ were used to account for possible ranges of soil parameters. The reasons for using these ranges. For all cases, $\mathrm{c}=0$ was applied to the entire zone of the slope mass for the post-rainfall condition; $\mathrm{c}=30 \mathrm{kPa}$ was applied to the abovegroundwater-table zone for the pre-rainfall condition. Although the result of calibration is influenced by the use of various values of $c$, the accuracy of slope displacement calculation is not. To obtain the calibrated values of $K, n, R_{f}$, and $\varphi$, horizontal lines were drawn at 30 $\mathrm{mm}$ (measured horizontal displacement from inclinometer 04-4 for the first event of slope movement). Values of $\mathrm{K}$ and $\mathrm{n}$ that represent the upper bound, the intermediate value, and the lower bound of $\phi$ that generate a slope displacement of $30 \mathrm{~mm}$ were selected as the back-analyzed values of soil parameters. A total of seven sets of $K, n$, and $R_{p}$ are used for evaluating the slope displacements induced by the subsequent events of rainfall (or groundwater table rises). Figure 8 shows a comparison of calculated and measured cumulative slope displacements at the location of $280.5 \mathrm{~m}$ from the crest of the slip surface (at inclinometer 04-4). The calculation of cumulative slope displacements assumed that a plastic (or irreversible) slope displacement occurs for each rainfall event. The cumulative slope displacement measured at $280.5 \mathrm{~m}$ for the crest of the slip surface is also shown. A good agreement between the measured and calculated slope displacements (with a maximum error of $10 \%$ ) can be seen. The fact that seven sets of input K, n, and $\mathrm{R}_{\mathrm{f}}$ all generate similar values of cumulative slope displacement reveals that the final results of calculation are insensitive to the input parameters provided that the values of $K, n$ and $R_{p}$, and $\varphi$ are calibrated using the first event of slope movement.

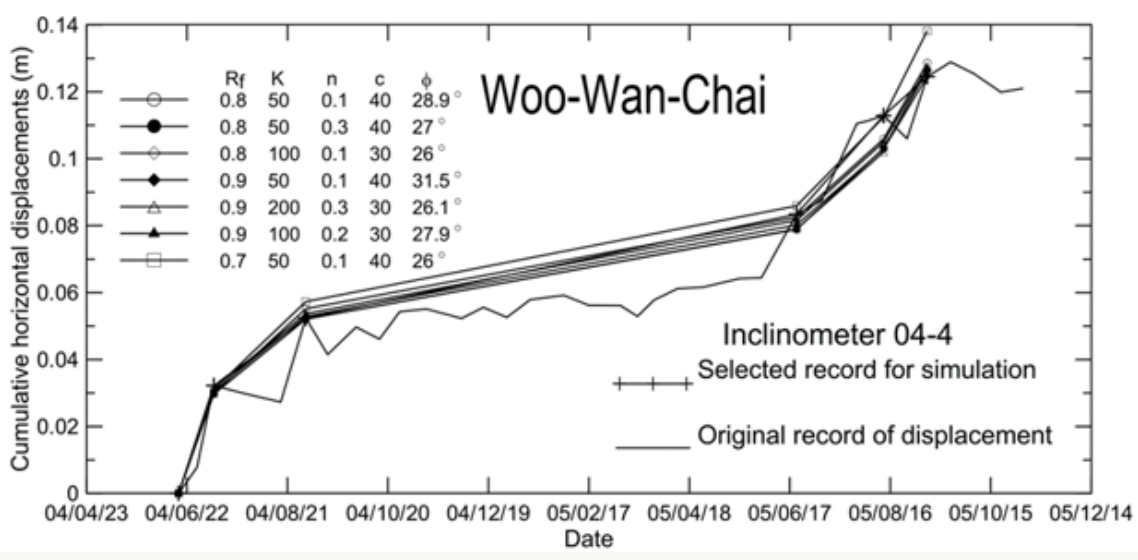

Figure 8: Comparison of measured and calculated long-term slope displacements for case history \#1.

\section{Case History: Ar-Li-San Slope}

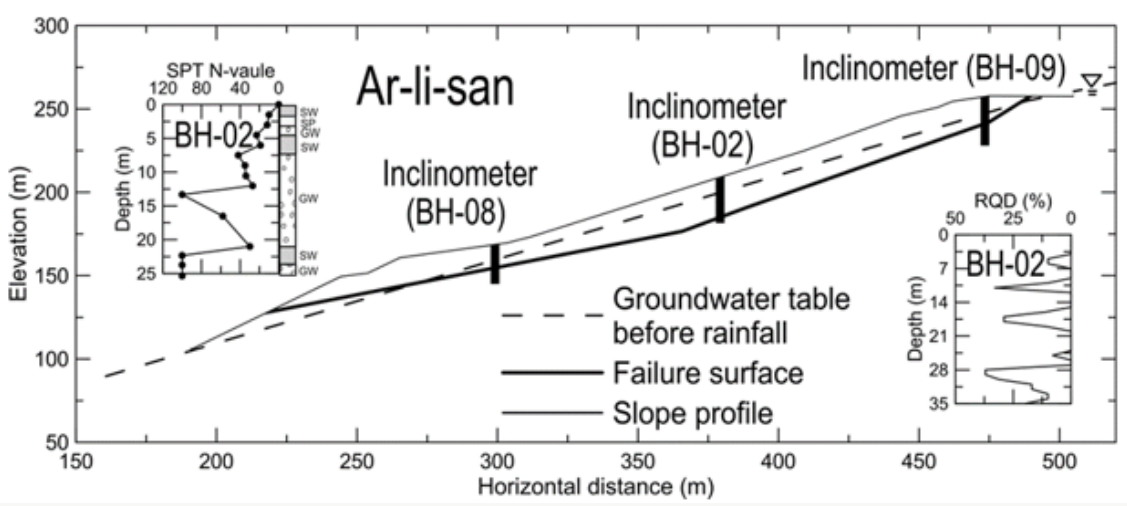

Figure 9: Slope profile of case history \#2 (Ar-Li-San).

Figure 9 shows the cross section of the Ar-Li-San slope which is on the same highway as the slope in case history no. 1 but at a different location. A maximum depth of slip surface of about $25 \mathrm{~m}$ has been detected by the inclinometers. The borehole data shown in Figure 9 suggest that the slip surface locates in highly weathered rock strata which frequently show RQD values as low as zero. Therefore, a soil-like material is likely to prevail along the slip surface, and $\varphi=26^{\circ}-35^{\circ}$ is assumed in the following analyses. Figure 10 shows the changes of safety factors associated with the fluctuation of the groundwater table. Figure 10 reveals a generally descending trend of safety factors in response to the generally ascending groundwater table during the rainy season. However, information on the performance of the slope during the rainy season is also lacking, as discussed for Figure 5. 


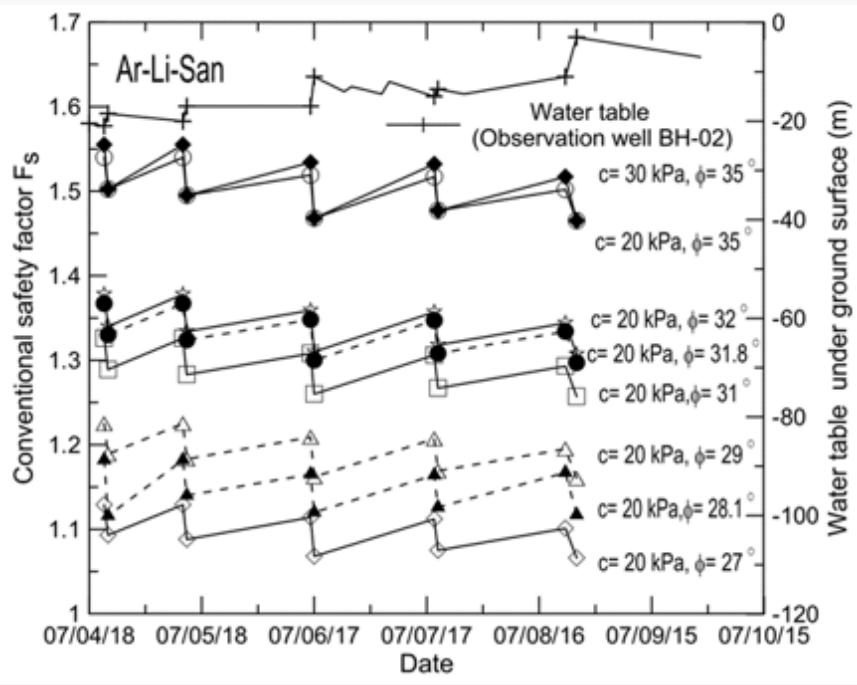

Figure 10: Sefety factors calculated using Janbu's slice method during the period of monitoring.
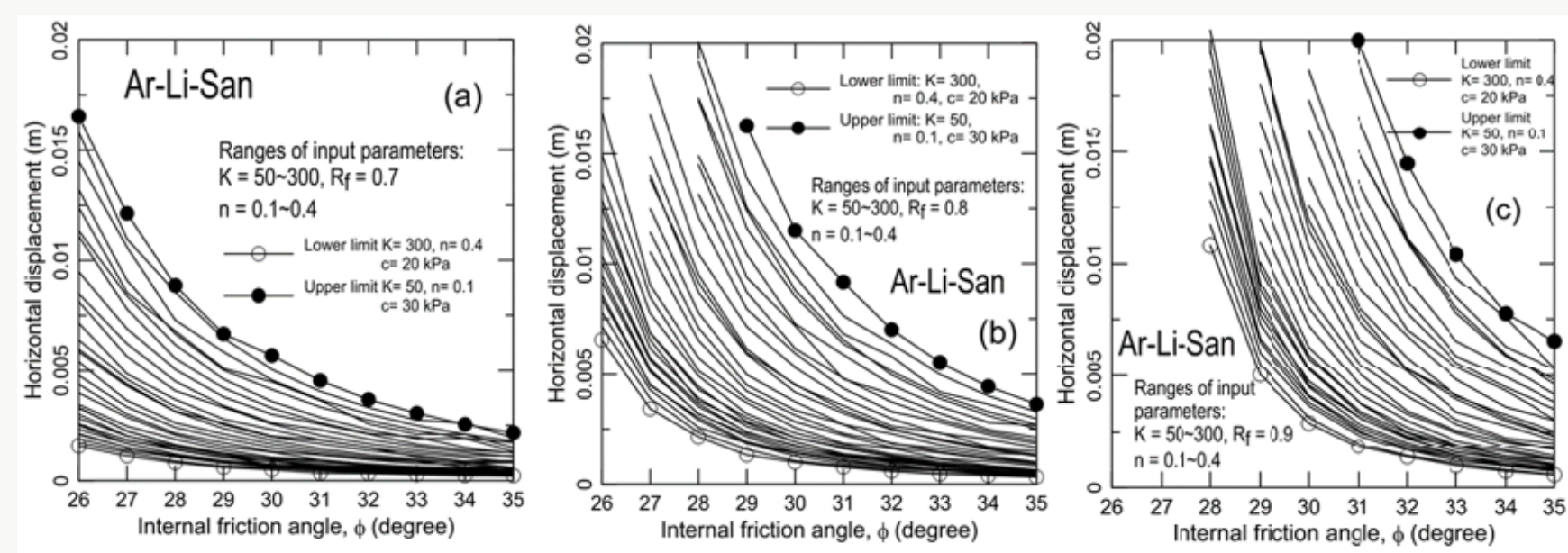

Figure 11: Parametric studies for the slope displacements using various input parameters: (a) $R_{f}=0.7 ;(b) R_{f}=0.8 ;(c) R_{f}=0.9$.

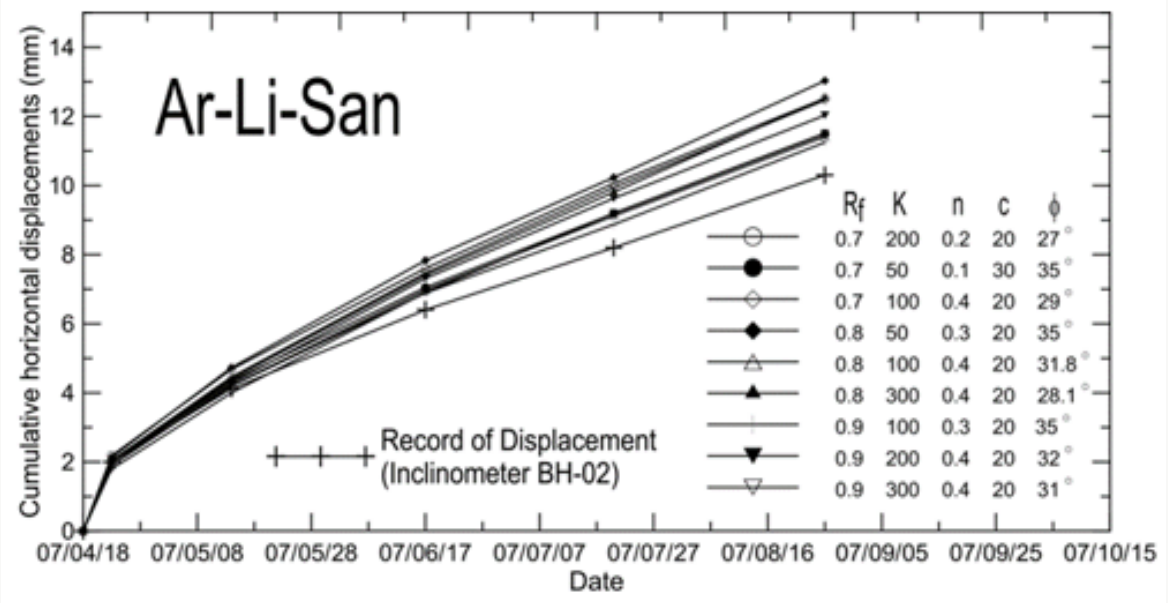

Figure 12: Comparisons of measured and calculated cumulative slope displacements for case history \#2.

Figures 11(a-c) show horizontal displacements at the location of $113 \mathrm{~m}$ from the crest of slip surface, calculated using $\mathrm{R}_{\mathrm{f}}=0.7,0.8$, and 0.9 , respectively. Similar to those used for case history \#1, K=
$50,100,200$, and $300 ; \mathrm{n}=0.1,0.2,0.3$, and 0.4 ; and $\varphi=26^{\circ} \mathrm{c}-35^{\circ} \mathrm{c}$ were used. A total of nine sets of $\mathrm{K}, \mathrm{n}$, and $\mathrm{R}_{\mathrm{f}}$ were back-calculated based on an approach similar to that used in case history no. 1 for a measured 
horizontal slope displacement of $3 \mathrm{~mm}$ from the inclinometer (BH02 ) in case history no. 2. Figure 12 shows comparisons between the measured and calculated cumulative slope displacements. The trends of all calculated curves of cumulative slope displacement are close to that of slope displacement during the rainy season. It can be seen that for the five simulated events, the percentage error ranges between $10 \%$ and $20 \%$, which is larger than that for case history no. 1 partially due to the fact that the slope displacement in the monitoring season was relatively small (a few mm). A 20\% error for slope displacement prediction is considered acceptable. This result confirms that the calculated cumulative slope displacement is insensitive to the input parameters provided that they are backcalculated from the first event of slope movement.

\section{Conclusion}

A mechanics-based procedure for predicting continuous slope displacements induced by periodic groundwater table changes was proposed. A limit-equilibrium-based finite displacement method (FFDM) previously proposed by the author was used to calibrate soil parameters based on two long-term records of periodic slope displacements induced by some intensive rainfall (or groundwater table fluctuations). The proposed approach consists of a calibration procedure that is used to find possible representative soil strength and displacement-related parameters based on the first event of slope movement induced by a groundwater table rise. These backcalculated soil parameters were then used to predict subsequent slope displacements in response to the groundwater table rise induced by intensive rainfall. Two case histories were used to verify the proposed approach. The effectiveness of the proposed method in predicting groundwater-table-induced instantaneous and cumulative slope movements was demonstrated. The proposed method requires little computer time to provide useful slopedisplacement-related information which cannot be achieved using conventional limit equilibrium or advanced numerical methods.

\section{Acknowledgement}

This study was financially supported by the Ministry of Science and Technology, Taiwan, under research grant MOST 101-2221-E-006-161-MY3.

\section{Appendix}

\section{Calculating local safety factors according to force equilibrium}

A local stress-based safety factor, $\mathrm{FS}_{\mathrm{i}}$, is defined as:

$$
F S_{i}=\frac{\tau_{f_{i}}}{\tau_{i}}=\frac{S_{f i}}{S_{i}}
$$

$\mathrm{S}_{\mathrm{fi}}$ : ultimate shear strength at the base of slice i

Ultimate shear strength at the base of slice $\mathrm{i}\left(\mathrm{S}_{\mathrm{fi}}\right)$ is derived from Mohr-Coulomb failure criterion:

$$
\begin{aligned}
& S_{f i}=\tau_{f i} \cdot \ell_{i}=C_{i}+N_{i}^{\prime} \cdot \tan \varphi \\
& C_{i}=c \cdot \ell_{i}=c \cdot B_{i} \cdot \sec \alpha_{i} \\
N_{i}^{\prime}= & \left(W_{i}-S_{i} \cdot \sin \alpha_{i}-\Delta X_{i}-U_{i} \cdot \cos \alpha_{i}\right) \cdot \sec \alpha_{i} \\
& U_{i}=u_{i} \cdot \ell_{i}=u_{i} \cdot B_{i} \cdot \sec \alpha_{i} \\
& \Delta X_{i}=X_{i}-X_{i-1}
\end{aligned}
$$

i- slice number ( $i=1,2, \ldots, n s ;$ ns: total number of slices)

$\mathrm{X}_{\mathrm{i}}, \mathrm{X}_{\mathrm{i}-1}$ - vertical inter-slice forces acting on the left and right sides, respectively, of slice $\mathrm{i}$.

$\ell_{i}, \mathrm{~B}_{\mathrm{i}}$ - length and width, respectively, of slice $\mathrm{i}$

$\mathrm{W}_{\mathrm{i}}$ - weight of slice $\mathrm{i}$

$\alpha_{i}$ - inclination angle of the base of slice i

c- cohesion intercept of soil

$\varphi$-internal friction angle of soil

The effective normal force acting on slice i $\left(N_{i}^{\prime}\right)$ expressed by Eq. (4) is based on the force equilibrium in the vertical direction $(\Sigma$ $\left.\mathrm{F}_{\mathrm{V}}=0\right)$. The differentials of $\mathrm{E}_{\mathrm{i}}$, namely $\Delta \mathrm{E}_{\mathrm{i}}\left(=\mathrm{E}_{\mathrm{i}}-\mathrm{E}_{\mathrm{i}-1}\right)$, can be derived from the force equilibrium in the horizontal direction $\left(\Sigma \mathrm{F}_{\mathrm{H}}=0\right)$, expressed as:

$$
\Delta E_{i}=-\frac{S_{f i}}{F S_{i}} \cdot \sec \alpha_{i}+\left(W_{i}-\Delta X_{i}\right) \cdot \tan \alpha_{i}
$$

The values of $X_{i}(i=1,---, n s)$ can be calculated based on the moment equilibrium at the center of slice base $\left(\Sigma M_{0}=0\right)$, expressed as:

$$
X_{i}=E_{i} \cdot \tan \theta_{i}
$$

Equation (8) is the derived from the moment equilibrium about the center of a slice base, with the assumption that the differential terms $X_{\mathrm{i}}$ and $\mathrm{E}_{\mathrm{i}}$ are negligibly small when the slice width is small. Calculated values of $X_{i}$ can be used in deriving values of $\Delta X_{i}$ (as expressed in Eq. 6) with known boundary values of $X_{i}$ (namely $X_{0}$ and $\mathrm{X}_{\mathrm{ns}}$ ).

\section{Constitutive stress-displacement relationships}

The shear stress $\left(\tau_{\mathrm{i}}\right)$ vs. shear displacement $\left(\Delta_{\mathrm{i}}\right)$ relationship at the base of slice $i$, is expressed by the following hyperbolic equation:

$$
\begin{aligned}
\tau_{i} & =\frac{\Delta_{i}}{a^{\prime}+b^{\prime} \cdot \Delta_{i}} \\
a^{\prime} & =\frac{1}{k_{\text {initial }}} \\
b^{\prime} & =\frac{R_{f}}{\tau_{f}}
\end{aligned}
$$

Where $\mathrm{k}_{\text {initial }}$ - initial value of shear spring constant; $\mathrm{R}_{\mathrm{f}}$ - failure ratio Normalizing Eq. (9) using $\tau_{\text {fi }}\left(=S_{\mathrm{fi}} / l_{\mathrm{i}}\right.$; from Eq. 2) yields:

$$
\frac{\tau_{i}}{\tau_{f}}=\frac{\Delta_{i}}{a+b \cdot \Delta_{i}}
$$


where

$$
\begin{aligned}
& a=a^{\prime} \cdot \tau_{f i}=\frac{\tau_{f}}{k_{\text {initial }}} \\
& b=b^{\prime} \cdot \tau_{f}=R_{f}
\end{aligned}
$$

The initial stiffness $\left(\mathrm{k}_{\text {initial }}\right)$ of the stress-displacement curve is an exponential function of effective normal pressure on the failure surface (or slice base), $\sigma_{n}^{\prime}$, expressed as:

$$
\begin{aligned}
& k_{\text {initial }}=K \cdot P_{a} \cdot\left(\frac{\sigma_{n_{i}}^{\prime}}{P_{a}}\right)^{n} \\
& \sigma_{n_{i}}^{\prime}=\frac{N_{i}^{\prime}}{B_{i} \cdot \sec \alpha_{i}}
\end{aligned}
$$

where

$\mathrm{K}, \mathrm{n}$ - material constants

$\mathrm{P}_{\mathrm{a}}$ - atmospheric pressure $(=98.1 \mathrm{kPa})$

\section{Displacement compatibility requirements}

Based on the displacement diagram that satisfies displacement compatibility as shown in Fig. A-1:

$$
\Delta_{2}=\Delta_{1} \cdot \frac{\cos \left(\alpha_{1}-2 \psi\right)}{\cos \left(2 \psi-\alpha_{2}\right)}
$$

where

$\psi$ - dilatancy angle ( $\psi=0$ is assumed in the present study)

The shear displacement of slice i $\left(\Delta_{\mathrm{i}}\right)$ can be related to the vertical displacement at the top of the slope $\left(\Delta_{0}\right)$ using:

$$
\Delta_{i}=\Delta_{1} \cdot \frac{\cos \left(\alpha_{1}-2 \psi\right)}{\cos \left(2 \psi-\alpha_{i}\right)}=\frac{\Delta_{o}}{\sin \left(\alpha_{1}-\psi\right)} \cdot \frac{\cos \left(\alpha_{1}-2 \psi\right)}{\cos \left(2 \psi-\alpha_{i}\right)}
$$

Equation (18) can be rewritten as:

$$
\Delta_{i}=\Delta_{o} \cdot f\left(\alpha_{i}\right)
$$

where

$$
f\left(\alpha_{i}\right)=\frac{1}{\sin \left(\alpha_{1}-\psi\right)} \cdot \frac{\cos \left(\alpha_{1}-2 \psi\right)}{\cos \left(2 \psi-\alpha_{i}\right)}
$$

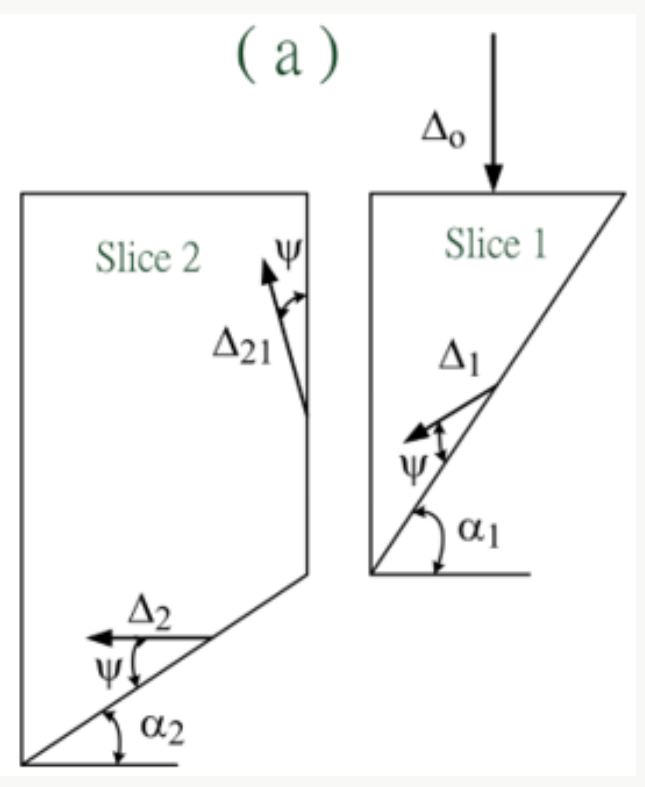

(b)

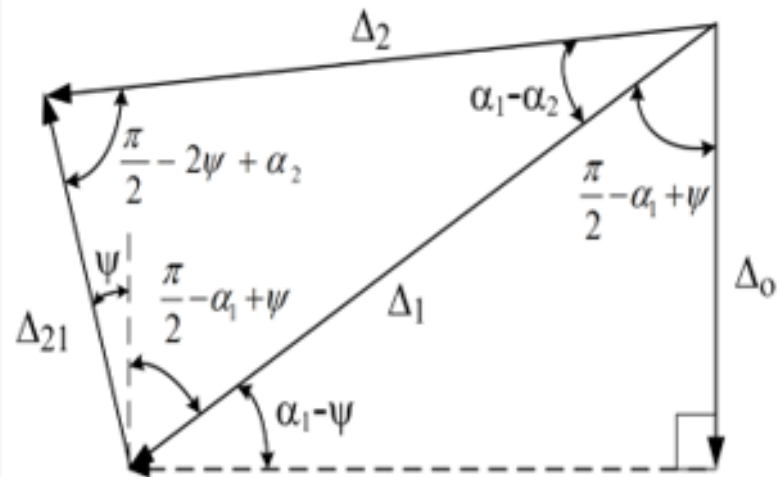

Figure A-1: Displacement diagram for two adjacent slices: (a) vectors of displacement, (b) displacement compatibility of slice displacement 


\section{Closed-form solution of slope displacement}

Based on the definitions of safety factors in Eq. (1), Eq. (12) can be rewritten as:

$$
F S_{i}=\frac{a+b \cdot \Delta_{i}}{\Delta_{i}}
$$

Substituting Eq. (20) into Eq. (21), the local stress-based safety factor $\left(\mathrm{FS}_{\mathrm{i}}\right)$ can be expressed as:

$$
F S_{i}=\frac{a+b \cdot \Delta_{o} \cdot f\left(\alpha_{i}\right)}{\Delta_{o} \cdot f\left(\alpha_{i}\right)}
$$

Based on the principle of force equilibrium in the horizontal direction $\left(\sum \mathrm{F}_{\mathrm{H}}=0\right)$, a summation of Eq. (7) for $\mathrm{i}=1$ - ns yields:

$$
\sum\left(\frac{S_{f i} \cdot \sec \alpha_{i}}{F S_{i}}\right)=\left[\sum\left(W_{i}-\Delta X_{i}\right) \cdot \tan \alpha_{i}\right]-E_{n s}+E_{o}
$$

$$
S_{f i}=\frac{C_{i}+\left(W_{i}-\Delta X_{i}-U_{i} \cdot \cos \alpha_{i}\right) \cdot \tan \varphi \cdot \sec \alpha_{i}}{1+\frac{\tan \varphi \cdot \tan \alpha_{i}}{F S_{i}}}
$$

$\mathrm{E}_{\mathrm{ns}}, \mathrm{E}_{0}$-horizontal forces at left and right, respectively, ends of sliding mass

Substituting Eqs. (22) and (24) into Eq. (23) yields:

$$
\begin{aligned}
\Delta_{o} \cdot \sum\left[\frac{C_{i}+\left(W_{i}-\Delta X_{i}-U_{i} \cdot \cos \alpha_{i}\right) \tan \varphi \cdot \sec \alpha_{i}}{1+\frac{\tan \varphi \cdot \tan \alpha_{i} \cdot \Delta_{o} \cdot f\left(\alpha_{i}\right)}{a+b \cdot \Delta_{o} \cdot f\left(\alpha_{i}\right)}}\right] \cdot\left[\frac{f\left(\alpha_{i}\right)}{a+b \cdot \Delta_{o} \cdot f\left(\alpha_{i}\right)}\right] \\
=\left[\sum\left(W_{i}-\Delta X_{i}\right) \cdot \tan \alpha_{i}\right]-E_{n s}+E_{o}
\end{aligned}
$$

Rearranging Eq. (25) for the unknown $\Delta_{0}$ yields:

$$
\Delta_{o}=\frac{\left[\sum\left(W_{i}-\Delta X_{i}\right) \cdot \tan \alpha_{i}\right]-E_{n s}+E_{o}}{\sum\left[\frac{C_{i}+\left(W_{i}-\Delta X_{i}-U_{i} \cdot \cos \alpha_{i}\right) \tan \varphi \cdot \sec \alpha_{i}}{\left.1+\frac{\tan \varphi \cdot \tan \alpha_{i} \cdot \Delta_{o} \cdot f\left(\alpha_{i}\right)}{a+b \cdot \Delta_{o} \cdot f\left(\alpha_{i}\right)}\right] \cdot\left[\frac{f\left(\alpha_{i}\right)}{a+b \cdot \Delta_{o} \cdot f\left(\alpha_{i}\right)}\right]}\right.}
$$

It can be seen that Eq. (26) is a closed-form expression of the slope crest displacement in the vertical direction $\left(\Delta_{0}\right)$, which is a nonlinear equation, requiring a few iterative calculations to attain a converged solution of $\Delta_{0}$.

\section{References}

1. Chang S K, Lee DH, Wu J H and Juang CH (2011) Rainfall-based criteria for assessing slump rate of mountainous highway slopes: A case study of slopes along Highway 18 in Alishan, Taiwan. Engineering Geology 118(3-4): 63-74.

2. Lee DH (2013) Slope management criteria for Alishan Highway based on database of heavy rainfall-induced slope failures. Engineering Geology 162(25): 97-107.

3. Kokusho T, Ishizawa T, Koizumi K (2011) Energy approach to seismically induced slope failure and its application to case histories. Engineering Geology 122(1-2): 115-128.

4. Huang CC (2013) Developing a new slice method for slope displacement analyses. Engineering Geology 157: 39-47.

5. Xiaoyu J, Janping Q, Chenghua W, Yu Z (2006) Computer simulation of landslides by the contact element method. Computers and Geosciences 32(4): 434-441.

6. Huang CC, Hsieh HY, Hsieh YL (2014) Slope displacement analyses using force-equilibrium-based finite displacement method and circular failure surface. Journal of GeoEngineering 3(1): 11-19.

7. Huang CC, Yeh SW (2015) Predicting periodic rainfall-induced slope displacements using force-equilibrium- based finite displacement method. Journal of GeoEngineering 10(3): 83-89.

8. Huang CC (2016) Back-calculating strength parameters and predicting displacements of deep-seated sliding surface comprising weathered rocks. International Journal of Rock Mechanics and Mining Sciences 88: 98-104.

9. Energy and Resources Research Laboratory of Industrial Technology Research Institute. Report on the site exploration for Wu-Wan-Zai landslide area in Chia-Yi (1999) county. The $5^{\text {th }}$ Maintenance Office, Directorate General of Highways, Ministry of Transportation and Communications.

10. Chang M, Chiu Y, Lin S, Ke TC (2005) Preliminary study on the 2003 slope failure in Woo-wan-chai area, Mt. Ali Road, Taiwan. Engineering Geology 80: 93-114.

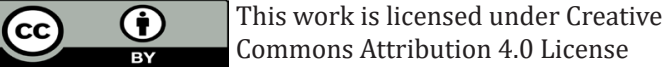

To Submit Your Article Click Here:

Submit Article

DOI: $10.32474 /$ OAJESS.2018.01.000117

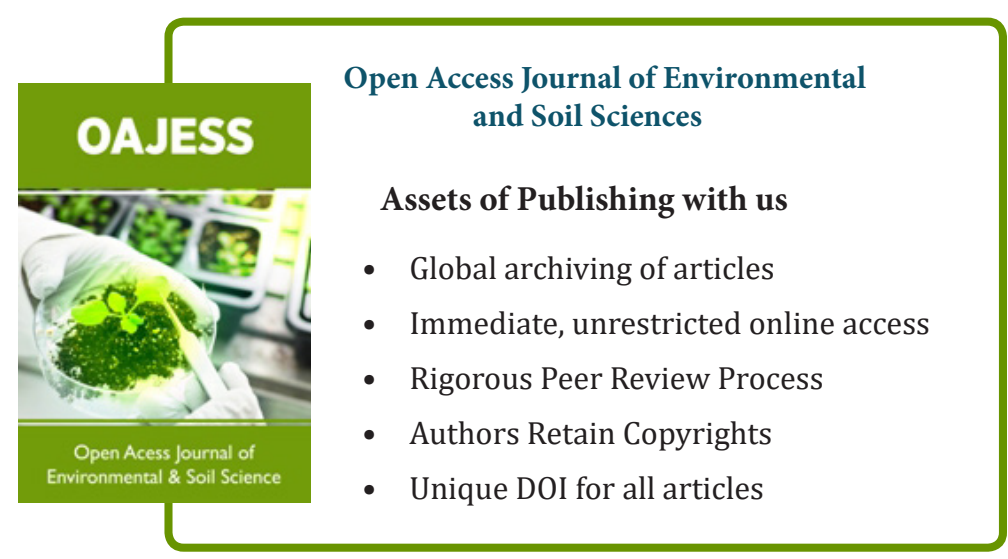

Citation: Ching-Chun Huang. A Mechanics-Based Procedure for Predicting Groundwater-Rise-Induced Slope Displacements. Open Acc J

Envi Soi Sci 1(4)-2018. OAJESS.MS.ID.000117. DOI: 10.32474/OAJESS.2018.01.000117. 